\title{
Enhancing usability using Near Field Communication for mobile application
}

\author{
Endar Wihidayat ${ }^{1, *}$, Ovide D.W. Ardi ${ }^{2}$ \\ ${ }^{1}$ Pendidikan Teknik Informatika dan Komputer, Universitas Sebelas Maret, Surakarta, Indonesia \\ ${ }^{2}$ D3 Teknik Informatika, Universitas Sebelas Maret, Surakarta, Indonesia
}

\begin{abstract}
Near Field Communication (NFC) as relatively new wireless communication technology pushes new challenges to application developers to make their applications easier to use and simpler to operate. This point of view known as usability element. Usability is one of the elements for creating good quality applications. This study aims to analyse the usability of mobile-based application embeds with NFC. We also try to evaluate usability in applications used by children. We developed an application called Receptionist which has a primary function as a communication tool between students, teachers and parents at a middle school. To know the impact of the NFC, the Receptionist input system is designed with two methods, via conventional navigation (using buttons) and via NFC. To understand the usability of each method, we do user testing and questioners on students. The results show, using the NFC there is a significant increase in usability attributes: efficiency, effectiveness, and learnability. On the other hand, there is decreases of user satisfaction comparing to conventional method. In general, this study demonstrates the potential of new input device technologies that can improve the usability of mobile-based applications.
\end{abstract}

\section{Introduction}

Many studies discuss the use of NFC in mobile applications. Related to usability purposes, most research on NFC focuses on improving the effectiveness, efficiency, and ease of use of the applications. The use of $\mathrm{NFC}$ is aimed at improving effectiveness in product identification [1]. Furthermore, another study shows the application of NFC is more efficient than barcodes [2]. Within the study, it has been demonstrated that $95 \%$ of participants agreed that the system was easy to use and easy to learn, with a pleasant interface. Using technology with NFC-enabled help older adults to make the technology easy to use, useful, and enhancing the sense of power [3]. Using an integrated application with NFC for helping children with language impairment proved that the application was easy to understand and learn [4].

Most of the studies do not mention the significance of NFC compared the standard navigation like touch screen buttons or keyboard. When a device is embedded with the NFC, it will the only way to perform certain functions. That situation won't let us know whether NFC is better than other input methods, for example using the button for navigation, or input form using a keyboard for entering the password for authentication. Furthermore, we try to analyze the usability impact of NFC on children. We want to know, is it better or is it matter to make faster input process using NFC, especially for children? So, this study is trying to answer those questions. We build an application, called Receptionist, that provides two ways of navigation to compare its significance. Furthermore, this research will be tested on children as one of the application users.

This research is divided into several sections. The second section will discuss general usability concepts in software, usability in mobile applications, NFC as input devices, usability components and measurement, and usability designed for children apps. The third section will discuss the methods used. The fourth section will show results. And finally, the conclusions of this article are in Section 5 .

\section{Usability, Mobile Application and Children Usability Testing}

\subsection{Software usability}

Usability is defined as the ease with which a user can learn to operate, prepare inputs for, and interpret the outputs of a system or component (IEEE Std 610.12-1990). Usability is one of key factor to create a high-quality software. International Organization for Standardization (ISO) standard divides software quality into six general categories of characteristics: functionalities, reliability, usability, effectiveness, maintainability and portability. Usability refers to some concepts such as execution time, performance, user satisfaction and ease of learning [5].

Based on the ISO 9126 (1991), usability is defined as a set of attributes in an application that is intended to meet the needs at the time of use and assessment in the process of use. These attributes are understandability, learnability,

* Corresponding author: endars@staff.uns.ac.id 
operability, attractiveness and usability compliance. In the 2001 edition of ISO/IEC 9126-1 define usability as the capability of the software product to be understood, learned and liked by the user, when used under specified conditions. Furthermore, based on the ISO 9241 standard, software is usable when it allows the user to execute his task effectively, efficiently and with satisfaction in the specified context of use. So this standard has three attributes: effectiveness, efficiency, and satisfaction.

Regarding usability, ISO develops several different standards but can be broken down into two categories, product-oriented standards (ISO 9126, 2001; ISO 14598, 2001) and process-oriented standards (ISO 9241, 1992/2001; ISO 13407, 1999). Both are applied to complement each other.

\subsection{Mobile Application Usability Challenge}

The term of mobile application is commonly used refer to software which runs on the mobile devices operation system such as Android, Windows Mobile and iOS. Nowadays, they are evolving rapidly, making ubiquitous information access at anytime and anywhere [6]. Developing applications for mobile devices that pay attention to usability factors is a new challenge. These challenges arise related to the characteristic of mobile devices which has limited hardware capabilities (such as small screen size, limited memory, limited processor, virtual keyboard), unreliable wireless network connections, and many disruptive use environments. Mobile devices have some uniqueness compared to desktop computers as taken from [6] which explains at least five characteristics that are considered still relevant for now.

Mobile Context: This term can be defined as an environmental condition when the users use their mobile devices. Environmental conditions are influenced by many variables such as user locations, the presence of objects such as vehicles, people. The weather, noise and lighting, etc. All these elements affect the usability of the application.

Connectivity: Mobile devices are connected to wireless networks that are not reliable compared to fixed networks (using LAN cable). Data transfer rates are affected by wireless networks used (normally, WIFI are more stable than cellular networks).

Screen Size: Screen size of touchscreen technology did not change significantly for a decade. And it does not seem to be a significant shift in the future, considering the portability and ergonomic factors of small screen size. What may be different in recent years is the use of an external or extended screen that has been enabled via wireless. However, the use of an extended screen is only possible in conditions where the user is not mobile and only works in a particular mobile context (for instance: indoor use).

Power and Processing Capability: Compared to a decade ago, processor capabilities have increased significantly, even multiplied. But the applications that are created also require an increasing resource. In general, mobile devices have lower specs than desktop devices.
Data Entry Method: Performing data entry on devices with small screen is a major challenge in application design. Virtual keyboard reduces speed and increases error. No precise mouse cursor also increases navigation errors. In the end, all lead to reduced convenience in the use of the application. In a study by [7], they simplified the application data entry method using NFC as a key feature. This study emphasizes the advantages of NFC which can represent the real-world actions (by tapping as if the user performs other physical activities such as pressing switches).

With those characteristics, in general, applications designed for mobile devices will emphasize simplicity by limiting the information displayed. The app developer will select the most necessary information to be presented.

\subsection{Near Field Communication (NFC) as Shortcut}

The NFC standards and protocols are based on RFID standards outlined in ISO / IEC 14443. The NFC is attached to a smartphone/tablet device that falls into the High-Frequency category at $13.56 \mathrm{MHz} \mathrm{NFC}$ works at close range, within a few centimetres range. It consists of an active device (has its own energy, for example, NFC Reader, smartphone or tablet), and passive devices (do not have their own energy, for example, NFC card-shaped tags, stickers, etc.in). Because it works at close range, then NFC tag needs to be taped or pasted onto the active device. NFC has three modes of communication: (1) reader/writer mode, (2) peer-to-peer mode and (3) card emulation mode. This new method of communication means new potential research in improving Quality of Service [8].

In 2006 Nokia issued the 6131-phone model which is the first smartphone device compatible with NFC. And in 2010 Samsung with Google released Nexus S, the first Android with NFC compatible. Within Android OSbased, the NFC function works by overriding or interrupting ongoing activities. This condition makes the event triggered by NFC can be a shortcut to trigger an action or command. This shortcut function is commonly used as an advantage or privilege of the NFC when this feature is first introduced by smartphone vendors. This study is trying to apply the advantages.

\subsection{Usability Measurement}

A study proposed five usability components with several measurement parameters as shown in Table 1 [5]. The component is a proposed improvement of two ISO usability standards of ISO 9241 and ISO 9126.

\subsection{Usability Testing for Children}

Usability testing refer to a process that employs people as testing participants who are representative of the target audience to evaluate the degree to which a product meets specific usability criteria [9]. Currently, mobile applications are commonly used by children in everyday life. But in contrast, usability study of mobile applications, especially applications for children is very 
little. Testing usability for children has several challenges such as child's tendency to remain silent during testing, span their attention during the test, and in the end making difficult to collect the data [10].

Table 1. Usability characteristic and measurement

\begin{tabular}{|l|l|}
\hline Characteristic & \multicolumn{1}{c|}{ Measurement } \\
\hline Effectiveness & $\begin{array}{l}\text { Percentage of task accomplished, Ratio } \\
\text { on failure of handling, Percentage of task } \\
\text { achieved per unit of time }\end{array}$ \\
\hline Efficiency & $\begin{array}{l}\text { Repetition number of failed command, } \\
\text { documentation or help's use frequency } \\
\text { error percentage, time spent on error, } \\
\text { time to achieve one task, number of good } \\
\text { and bad characteristics recalled by users, } \\
\text { number of available commands not } \\
\text { called upon }\end{array}$ \\
\hline Satisfaction & $\begin{array}{l}\text { percentage user favorable and } \\
\text { unfavorable comments, number of times } \\
\text { that user expresses his frustration, rating } \\
\text { scale for user satisfaction with functions } \\
\text { and characteristics }\end{array}$ \\
\hline Security & $\begin{array}{l}\text { access audibility, access controllability, } \\
\text { data corruption prevention, data } \\
\text { encryption }\end{array}$ \\
\hline Learnability & \begin{tabular}{l} 
time to learn \\
\hline
\end{tabular} \\
\hline
\end{tabular}

Children are very few in providing feedback and only focus on running the applications. Different child ages require different test adaptations. Commonly, children age is divided into three ranges, preschool (2-5 years), elementary school (5-10 years) and middle school (10-14 years).

Pre-schoolers require the most extensive adaptations of usability testing because their attention span, their motivation to please adults, and their ability to adjust to strange surroundings and new people may change from one moment to the next [11]. [11] recommends seven things need to be prepared for usability testing in children: (1) making a comfortable and child-friendly lab and (2) using a familiar device input. (3) Use laboratory equipment as effectively as one unobtrusively as possible. A one-way mirror is not recommended because it keeps children out of a given task (grooming behaviour). (4) When planning a series of tasks, switch the order around for different children. (5) Screening the children who have at least some experience with the computer, (6) but, exclude the children who have computer expertise (they have advanced computer skill). (7) Not to use our own children or our colleague's children as usability testing participants.

\subsection{Receptionist Main Feature}

Receptionist has several actors and features as shown in Table 2.
Table 2. Main feature of Receptionist

\begin{tabular}{|l|l|l|l|}
\hline $\begin{array}{l}\text { Main } \\
\text { Functional: }\end{array}$ & Actor & $\begin{array}{l}\text { Detail } \\
\text { functional }\end{array}$ & NFC \\
\hline $\begin{array}{l}\text { SMS } \\
\text { Broadcast }\end{array}$ & Teacher/Admin & SMS to a parent & Y \\
\cline { 2 - 4 } & Teacher/Admin & SMS broadcast & Y \\
\hline Phone call & $\begin{array}{l}\text { Teacher, } \\
\text { Students }\end{array}$ & $\begin{array}{l}\text { Phone call to } \\
\text { parents }\end{array}$ & Y \\
\hline SMS & Student & SMS to parent & Y \\
\hline Student Call & $\begin{array}{l}\text { Parents, } \\
\text { Teachers }\end{array}$ & $\begin{array}{l}\text { Students call } \\
\text { via speaker }\end{array}$ & Y \\
\hline \multirow{2}{*}{$\begin{array}{l}\text { Mata } \\
\text { Management }\end{array}$} & $\begin{array}{l}\text { Teacher/Admin } \\
\text { Import and } \\
\text { Manage } \\
\text { Student Data }\end{array}$ & N \\
\cline { 2 - 4 } & Teacher/Admin & Manage user & N \\
\cline { 2 - 4 } & Teacher/Admin & Voice Setting & N \\
\cline { 2 - 4 } & Teacher/Admin & Web Setting & N \\
\cline { 2 - 4 } & Teacher/Admin & SMS Setting & N \\
\cline { 2 - 4 } & Teacher/Admin & NFC Setting & N \\
\hline
\end{tabular}

As shown in Table 2, not all navigation supported by NFC. Using a NFC Tag card, only one command can be provided. So, the user has one command that can be assigned using a NFC tag. User testing will be performed on function with the student (children) as the actor and only function with available NFC navigation. In Fig. 1 we can see the user interface of Receptionist.

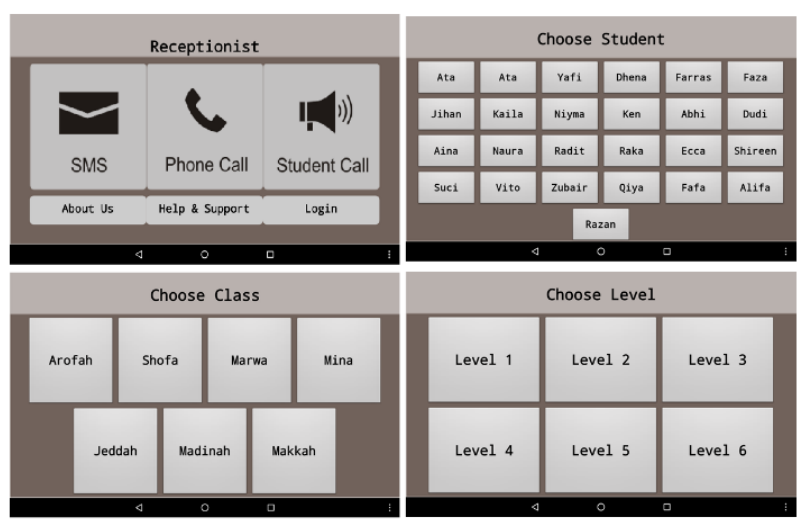

Fig 1. Receptionist user interface

\subsection{Receptionist Architecture}

The receptionist is installed in the school hall and administration room. Using acrylic case with extended antenna for NFC as shown in Fig. 2. The Receptionist connected to the WIFI network as a data path to the server and attached to an external sound system for student call function. The tablet has SMS and Call capability via cellular networks to perform SMS and phone call functions (Fig. 3). 


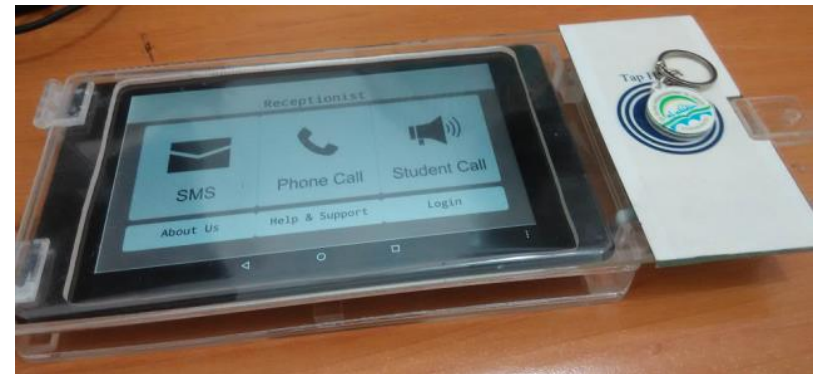

Fig 2. Receptionist installed tablet

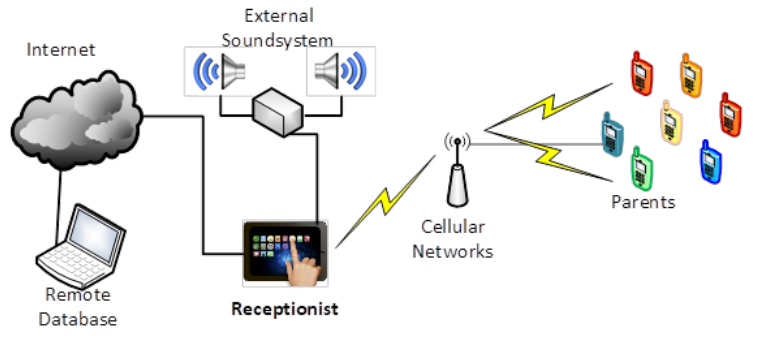

Fig 3. Receptionist architecture

\section{Research Method}

Two commonly used methodologies for testing usability are experimental testing within the lab and by field testing or real mobile context testing. Two commonly used methodologies for testing usability are experimental testing within the lab and field testing or real mobile context testing. The advantages of the lab experiment are: (1) full control of the experiment, (2) easy to measure usability attributes, at the same time exclude the irrelevant attributes, and (3) allowing the use of audio and video recording to capture user reactions during testing. [6]. Testing is conducted in a class (own participants class) which makes students feel comfortable. Testing is guided by a moderator. The moderator will guide the task to be done and record the time required to complete each task. Moderators will also be given a hidden video recorder, so hopefully does not affect the spontaneity of the attitude of the user. To help the process of data retrieval, then before usability testing the participants given a way of thinking aloud protocol.

\subsection{Usability Test Participants}

With 20 testing participants than at least 95\% usability problems will be found [12]. As much as 28 children with the variation of age 12-13 years who plays as a student chosen taking the test. Participants were selected randomly from sixth-grade students of International Islamic Elementary School (SDII) Al Abidin (private elementary school at Central Java Province, Indonesia). Following the guidelines described in Section 2.6, all students have sufficient background using mobile devices and also familiar with touchscreen input devices.

\subsection{Usability Components and Data Collection}

Usability measurements were taken from [5] as we can see at Table 3. The parameters used in user testing are tailored to the research context that aims to compare the usability between conventional methods (navigation using touchscreen button) and NFC methods. Table 3 shows the chosen measurement parameters.

Table 3. NFC usability testing components

\begin{tabular}{|c|c|c|}
\hline $\begin{array}{l}\text { Usability } \\
\text { Component }\end{array}$ & Measurement & $\begin{array}{l}\text { Data } \\
\text { collection/capturing } \\
\text { method }\end{array}$ \\
\hline Effectiveness & $\begin{array}{l}\text { Number of } \\
\text { successful task } \\
\text { Number of error }\end{array}$ & $\begin{array}{l}\text { Video record of testing } \\
\text { process }\end{array}$ \\
\hline Efficiency & $\begin{array}{l}\text { Time to achieve } \\
\text { one task }\end{array}$ & $\begin{array}{l}\text { Video record of testing } \\
\text { process }\end{array}$ \\
\hline Satisfaction & $\begin{array}{l}\text { Percentage of } \\
\text { users favorable } \\
\text { and unfavorable } \\
\text { comments }\end{array}$ & Questioners \\
\hline Learnability & $\begin{array}{l}\text { Percentage of } \\
\text { successful user to } \\
\text { accomplish task } \\
\text { on first trial }\end{array}$ & $\begin{array}{l}\text { Video record of testing } \\
\text { process }\end{array}$ \\
\hline
\end{tabular}

For questioners, we adopted the questions from Software Usability Scale (SUS). SUS is known as "quickand-dirty" usability scale [13], but for preliminary research, it is sufficient to demonstrate the effect of NFC on usability. Because of the mobile context and the user's context (children), it is necessary to adapt the questions that to be more easily to understand by children. There are 15 questions used as shown in Table 4.

Table 4. Questioners for usability testing

\begin{tabular}{|l|l|}
\hline No & \multicolumn{1}{|c|}{ Question } \\
\hline 1 & The application is running fast \\
\hline 2 & No found error during operation \\
\hline 3 & No trouble when first use \\
\hline 4 & I'm very sure to determine the next step \\
\hline 5 & It's no need extra time to learn \\
\hline 7 & Sometimes I felt quite tense when using this app \\
\hline 8 & I do not need an assistant for use this app \\
\hline 9 & I enjoy my moments using this app \\
\hline 10 & The application is fun \\
\hline 11 & This app is very easy to understand \\
\hline 12 & I want to use this app in everyday life \\
\hline 13 & The design is quite attractive \\
\hline 14 & It's easy and fast to move between pages \\
\hline 15 & At the first start, it's easy to find the necessary navigation \\
\hline
\end{tabular}




\subsection{Testing scenario}

This research focus to know the effect of NFC implementation for mobile app usability, specifically for children. So, the tested functions are only functions with alternative NFC navigation. Table 5 shows three tasks of function and the action flow for accomplishing the tasks, via button vs. via NFC.

Table 5. Action flow via button and via NFC

\begin{tabular}{|c|c|c|}
\hline \multirow{2}{*}{ Function } & \multicolumn{2}{|c|}{ Action Flow } \\
\hline & Via Button & Via NFC \\
\hline SMS & $\begin{array}{l}\text { Home } \rightarrow \text { Pick SMS } \rightarrow \\
\text { Pick Level } \rightarrow \text { ick Class } \\
\text { Pick Student } \rightarrow \text { SMS } \\
\text { Sent] }\end{array}$ & $\begin{array}{l}\text { Home } \rightarrow \text { [NFC } \\
\text { Tap] Pick SMS - } \\
\text { [SMS Sent] }\end{array}$ \\
\hline Phone call & $\begin{array}{l}\text { Home } \rightarrow \text { Pick Phone } \\
\text { Call Pick Level Pick } \\
\text { Class } \rightarrow \text { Pick Student } \rightarrow \\
\text { [Phone called] }\end{array}$ & $\begin{array}{l}\text { Home } \rightarrow \text { [NFC } \\
\text { Tap] } \rightarrow \text { Pick phone } \\
\text { call } \rightarrow \text { [Phone } \\
\text { called] }\end{array}$ \\
\hline $\begin{array}{l}\text { Students } \\
\text { Call }\end{array}$ & $\begin{array}{l}\text { Home } \rightarrow \text { tudents Call } \rightarrow \\
\text { Pick Level } \rightarrow \text { Pick Class } \\
\rightarrow \text { Pick Student } \\
{[\text { Student Called] }}\end{array}$ & $\begin{array}{l}\text { Home } \rightarrow \text { [NFC } \\
\text { Tap] } \rightarrow \text { Pick } \\
\text { student } \quad \text { call- } \\
\text { [Phone called] }\end{array}$ \\
\hline
\end{tabular}

\section{Results and Analysis}

From the questioner's results, it can be seen that children are more satisfied using the button (Fig 3), even there is no significant gap. Furthermore, noticeable differences such as ease of navigation to start the task show that children find it difficult to start using NFC.

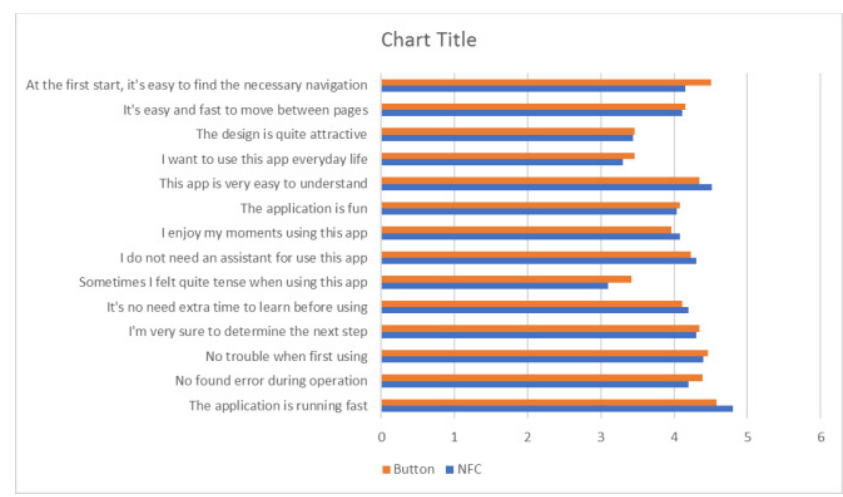

Fig 3. Questioner results

The use of NFC was also caused more tension than using a button which is understandable because NFC is not familiarly used as input devices among children. From the unfavorable comment gathered it is known that 12 participants criticize application user interface that less appealing. This result is matched with the questionnaire result (third question). Testing result shows that the NFC is more efficient to accomplish the tasks. The average time required for a single task is 3.5 seconds, a lot different when using a button that takes an average of 8 seconds. Using NFC, students can also complete tasks more effectively. Each method has a failure number while performing the task. If the NFC is due to the less sensitive of the sensor (this is ensured due to the use of the extended antenna that aims to increase the NFC range, originally laid back of the tablet but extend to the side as shown in
Fig. 2). Button method failure comes from the interrupt timer which is activated. It happens when the student takes too long for choosing the class name or the student name.

\section{Conclusion and Discussion}

This research is in the early stages to know the role of NFC to increase usability, especially at mobile applications for children. From the preliminary analysis result, it is known unsurprisingly that efficiency, effectiveness and learnability factor are increased by NFC. But in contrast, user satisfaction was decreased.

During the observation, the authors' personal opinion predicted that the speed and outcome, for children, were not the only goal they want to. For children, a longer process to interact is more fun. So, the main feature NFC that speeds up the process actually reduces their fun. Another thing that may affect children's user experience is the fact that all participants are still unfamiliar with NFC, in contrast, they are already familiar with the touchscreen device. With the difference between the NFC and the buttons which is not significant, if they are familiar with both input methods, the results may be different. Suggestions for further research, for children, NFC needs to be applied not only to finish the task faster but also more fun. The developer got extra time by implementing the NFC (because of the faster process). Extra time can be used to make better feedback to users after finished the task, and also could be a more fun way such as displaying fun messages for the users.

\section{References}

1. M. Khosravi, M. Karbasi, A. Shah, I. A. Brohi, and N. I. Ali, An adoption of halal food recognition system using mobile Radio Frequency Identification (RFID) and Near Field Communication (NFC), Proc. - 6th Int. Conf. Inf. Commun. Technol. Muslim World, ICT4M 2016, pp. 70-75 (2017)

2. A. Landman et al., "Efficiency and usability of a near field communication-enabled tablet for medication administration," J. Med. Internet Res.,16, no. 6 (2014)

3. W. M. Lim, P. Teh, P. K. Ahmed, A. H. S. Chan, S. Cheong, and W. Yap, Enhancing the Sense of Power and User Adoption in Gerontechnology: An Experimental Investigation of Near-Field Communication Lighting Systems, Proc. 2016 IEEE IEEM, pp. 1-5 (2016)

4. M. Luisa Lorusso, E. Biffi, M. Molteni, and G. Reni, "Exploring the learnability and usability of a near field communication-based application for semantic enrichment in children with language disorders," Assist. Technol., vol. 0, no. 0, pp. 1-12 (2017)

5. A. Abran, A. Khelifi, W. Suryn, and A. Seffah, "Usability meanings and interpretations in ISO standards," Softw. Qual. J., vol. 11, no. 4, pp. 325338 (2003)

6. D. Zhang and B. Adipat, "Challenges, Usability, Methodologies, and Issues in the Usability Testing of 
Mobile Applications," Int. J. Human-Computer ..., 18, no. 3, pp. 293-308 (2005)

7. S. L. Ghìron, S. Sposato, C. M. Medaglia, and A. Moroni, NFC ticketing: A prototype and usability test of an NFC-based virtual ticketing application, Proc. - 2009 1st Int. Work. Near F. Commun. NFC 2009, pp. 45-50 (2009)

8. V. Coskun, B. Ozdenizci, and K. Ok, A survey on near field communication (NFC) technology, Wirel. Pers. Commun., 71, no. 3, pp. 2259-2294 (2013)

9. J. Rubin and D. Chisnel, Handbook of Usability Testing, Second Edition: How to Plan, Design, and Conduct Effective Tests Published, 2nd ed., no. 1. Indiana: Wiley Publishing, Inc. (2008)
10. A. Donker and P. Reitsma, Usability Testing With Young Children, Interact. Des. Child., pp. 43-48 (2004).

11. L. Hanna, K. Risden, and K. Alexander, "Guidelines for usability testing with children," Interactions, 4, no. 5, pp. 9-14 (1997).

12. L. Faulkner, Beyond the five-user assumption: Benefits of increased sample sizes in usability testing, Behav. Res. Methods, Instruments Comput., 35, no. 3, pp. 379-383 (2003).

13. J. Sauro and J. Lewis, Quantifying the User Experience Practical Statistics for User Research. Elsevier Inc. (2012). 